\title{
The eye-tracking of social stimuli in patients with Rett syndrome and autism spectrum disorders: a pilot study*
}

\author{
Rastreamento do olhar para estímulos sociais em pacientes com síndrome de Rett e \\ transtornos do espectro do autismo: estudo piloto \\ José Salomão Schwartzman', Renata de Lima Velloso², Maria Eloísa Famá D’Antino', Silvana Santos³
}

\begin{abstract}
Objective: To compare visual fixation at social stimuli in Rett syndrome (RT) and autism spectrum disorders (ASD) patients. Method: Visual fixation at social stimuli was analyzed in 14 RS female patients (age range 4-30 years), 11 ASD male patients (age range 4-20 years), and 17 children with typical development (TD). Patients were exposed to three different pictures (two of human faces and one with social and non-social stimuli) presented for 8 seconds each on the screen of a computer attached to an eye-tracker equipment. Results: Percentage of visual fixation at social stimuli was significantly higher in the RS group compared to ASD and even to TD groups. Conclusion: Visual fixation at social stimuli seems to be one more endophenotype making RS to be very different from ASD.
\end{abstract}

Keywords: Rett syndrome, autism spectrum disorders, social cognition, eye tracking.

\section{RESUMO}

Objetivo: Comparar a fixação visual em estímulos sociais em pacientes com síndrome de Rett (SR) e com transtornos do espectro do autismo (TEA). Método: Fixação visual em estímulos sociais foi analisada em 14 pacientes do sexo feminino com SR (idades entre 4 e 30 anos), 11 pacientes do sexo masculino com TEA (idades entre 4 e 20 anos), e 17 crianças do sexo feminino com desenvolvimento típico (DT). Os participantes foram expostos a três figuras diferentes (duas figuras de faces humanas e uma figura contendo estímulo social e não social) apresentadas por 8 segundos cada uma no monitor de um computador acoplado a um equipamento de rastreamento de olhar. Resultados: A porcentagem de fixação visual em estímulos sociais foi significativamente maior no grupo SR do que no grupo TEA e mesmo no grupo DT. Conclusão: A fixação visual em estímulos sociais parece ser mais um dos endofenótipos que esclarecem as diferenças entre SR e TEA.

Palavras-chave: síndrome de Rett, transtornos do espectro do autismo, cognição social, rastreamento do olhar.

Although Rett syndrome (RS) has been considered a manifestation of autism spectrum disorders (ASD) as well as a genetic model of $\mathrm{ASD}^{1}$, many aspects peculiar to each of these conditions make them very different and deserve to be even more clarified, so that diagnosis and therapeutic and educational interventions can be as effective as possible for one and other condition.

$\mathrm{RS}$ is characterized by severe neuromotor, cognitive and communicative impairments. The severity of neuromotor impairments determines the level of global apraxia, resulting in loss or non-development of gait and purposeful use of hands, and in serious respiratory, gastrointestinal and orthopedic disturbances. Most of them do not develop any kind of speech. About 60\%-70\% develop with epileptic seizures. The empirical observation of RS patients points to a relative preservation of social domain, as they have a very intense look and somehow respond to social stimuli. The etiology of RS has strongly been associated with mutations in MECP2 gene ${ }^{2,3,4}$, and more recently with alterations in CDKL5 and FOGX1 in some cases ${ }^{5,6}$. Although it has been

*Clínica de Transtornos do Espectro do Autismo do Programa de Pós-graduação em Distúrbios do Desenvolvimento da Universidade Presbiteriana Mackenzie, Sao Paulo, SP, Brasil.

\footnotetext{
${ }^{1}$ Universidade Presbiteriana Mackenzie, Programa de Pós-Graduação em Distúrbios do Desenvolvimento, Sao Paulo SP, Brasil;

${ }^{2}$ Universidade Presbiteriana Mackenzie, Clínica de Transtornos do Espectro do Autismo, Sao Paulo SP, Brasil;

${ }^{3}$ Divisão de Informação e Pesquisa da Associação Brasileira de Síndrome de Rett de São Paulo - Abre-Te, Sao Paulo SP, Brasil.

Correspondence: José Salomão Schwartzman; Rua França Pinto, 941; 04016-034 São Paulo SP, Brasil; E-mail: josess@terra.com.br

Conflict of interest: There is no conflict of interest to declare.
}

Received 02 December 2014; Received in final form 20 December 2014; Accepted 09 January 2015. 
known as a female condition, affected males with a different phenotype have been reported ${ }^{7,8}$. RS is present in one of every 10,000-12,000 girls at 12 years-old. The severe limitations of RS patients make almost impossible to assess their cognitive and communicative abilities with the available batteries developed for such finality.

ASD are described as neurobiological conditions characterized by common impairments in social interaction, communication and behavior. Although the variable level of severity, the social domain is always very atypical, what is one of the most indicative aspects of such disorders. Social cognition is frequently poor. Neuromotor abilities are usually preserved in patients with an ASD. Altered speech is very frequent, but most of the individuals with ASD have physiological conditions to speak. ASD are associated with some level of intellectual disability in about $50 \%$ of the cases ${ }^{9}$, and with epilepsy in about $20 \%^{10,11}$. The etiology of ASD is multifactorial, and although a number of biological markers have already been identified, none of them can be considered pathognomonic or specific for ASD. Such disorders are more prevalent in males than in females, in a proportion of 4-5:1, and its incidence has been increasing in an astonish way ${ }^{12}$. There are many instruments developed for screening ASD and assessing different abilities of these individuals.

Eye tracking technology has been increasing the possibilities of understanding patients both with RS and ASD. Using such technology, it was possible to evidence by the first time and objectively the intentionality of RS patients' look $^{13}$, what opened a new door for understanding their cognitive, communicative and social functioning. For the first time as well, this technology allowed to determine patterns of visual fixation in naturalistic social situations as predictors of social competence in patients with autism ${ }^{14}$, and soon after some aspects of eye tracking began to be used as outcome measures in studies on $\mathrm{ASD}^{15}$.

The objective of this study was to compare the visual fixation at social stimuli in patients with RS and ASD with the use of eye tracking technology

\section{METHOD}

This study comprised 14 females with RS, 11 males with ASD, and 17 female children with typical development (TD).

RS patients (mean age $12.4 \pm 7.3$ years, range 4 -30 years) were recruited from Brazilian Rett Syndrome Association, according to the desire of their parents to let them participate in the study. All of them were clinically diagnosed by the same neurologist and were submitted to the genetic tests for MECP2 mutations: results were negative for two patients, inconclusive for other two, and different mutations were identified for the remaining ten: T158M (2), R294X (2), R106W (2), R306C (1), P152R (1), C236dupC (1), C.1164-del-11 (1).

ASD patients (mean age $8.5 \pm 4,4$ years, range $4-20$ years) were randomly recruited from ASD Clinic of the Postgraduation
Program on Developmental Disorders at Mackenzie Presbyterian University (ASD/MACK). All of them received ASD diagnoses after physical and neurological examinations, neuropsychological and speech assessments, according to the standardized protocol applied by the same multidisciplinary team.

TD children (mean age $5.1 \pm 0.9$ years, range $4-7$ years) were students of a same private school whose parents agreed with their participation in the study.

The research protocol was approved by the Ethics Committee of Mackenzie Presbyterian University, and written consent was obtained for all participants.

RS and ASD patients were assessed at ASD/MACK, where a Tobii 1750 eye tracker (Tobii Technology, 2005) with ClearView software was used to present the stimuli on a 17 " monitor with resolution of $1.280 \times 1.024$ pixels. TD children were assessed at a classroom in the school they were attending, with the use of a portable Mirametrix S2 Eye Tracker version 1.14981.24 with Eye Tracking Viewer software version 2.5.0.152, attached to a laptop with a 15 " monitor having resolution of $1.024 \times 768$ pixels.

Before presentation of stimuli for each patient, the equipment is calibrated in order to register peculiar characteristics of the patient's eyes so that gaze data can be calculated. For such calibration, the patient has to look at a point moving to all directions on the screen. Both eye trackers are able to detect different parameters during visual movements, such fixation and saccadic movements, and allow registering in real time the pattern of visual movements considering the previously stored data. It is possible to select target areas for data analysis. The softwares generate a file with relevant data for recovering the patient's eye tracking during the presentation of stimuli, registering how many times and how long (in milliseconds) the patient looked at the target area on the monitor.

Participants were seated about $50 \mathrm{~cm}$ from the monitor. RS and ASD patients too young or with intense body and head movements were seated on the lap of their parents (or caregivers), who kept their eyes closed during assessment. After calibration, three different pictures were presented for 8 seconds each, after the instruction "Look at the screen!". Before each picture, a black plate with a white circle in the center was presented for 5 seconds, so that the user could look again at the center of the monitor and move the gaze from the area where was looking at in the previous picture.

Picture 1 represented children faces with affective appeal; picture 2, a happy human face; and picture three was designed with a baby at the left side and a clock at the right side. Target areas for data analysis selected in pictures 1 and 2 included eyes, nose and mouth; the target areas in picture 3 were both the baby and the clock (Figure 1). All images were used in accordance with legally authorized rights.

Each user's total visual fixation time in milliseconds on the target areas was converted into seconds and then into percentage, considering the total presentation time of $8 \mathrm{sec}$ onds. Mean and standard deviation of such percentages were 

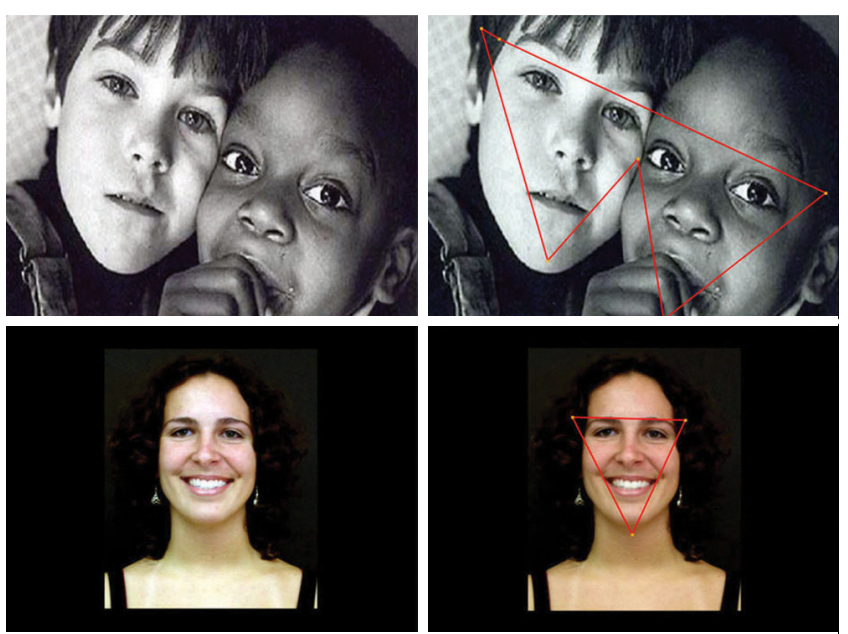



Clean pictures

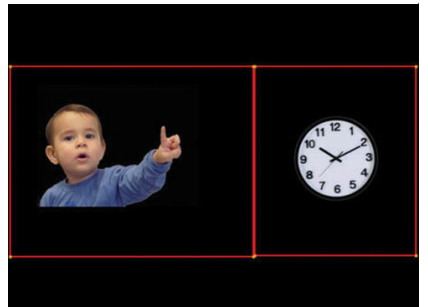

Selected areas
Figure 1. Pictures presented during testing and target areas selected for data analysis.

calculated for each group (RS, ASD and TD) and compared using analysis of variance (ANOVA) and t-test. Person's correlations were calculated to check associations between age and visual fixation time.

\section{RESULTS}

RS group looked at target areas significantly longer than ASD group and even than TD group (Table 1; Figure 2). RS and TD groups showed similar visual fixation only when the clock of picture 3 was considered the target area $(p=0.134)$. No significant difference was found out regarding visual fixation at target area of picture 1 when comparing ASD and TD groups $(\mathrm{p}=0.061)$.

Interesting findings refer to correlations between age and percentage of visual fixation at target areas (Table 2). In RS group, significant negative correlations were observed regarding pictures $1(\mathrm{r}=-0.56)$ and $2(\mathrm{r}=-0.47)$, and a positive but not significant correlation for picture 3 when the target was the clock $(\mathrm{r}=0.31)$. It means that older RS patients looked shorter time at social stimuli (human faces) and longer time at non-social stimuli (clock). Even when the oldest RS patient (30 years old, who in fact looked at target areas much shorter than the others RS participants), was not considered in this analysis, correlations continued strongly negative. On the other hand, such correlations in ASD group were not significant at all, even considering a moderate positive correlation regarding picture 2 , which would mean that older ASD patients looked longer at a happy woman face (but not at children faces). Finally, positive correlations were significant in TD group regarding all three social stimuli, without any correlation regarding non-social stimuli (clock); that is, older typically developing children looked at target areas longer than younger ones.

\section{DISCUSSION}

This is the first study to compare eye tracking of social (human faces) and non-social (clock) stimuli in RS and ASD patients, and differences in the pattern of visual fixation at such stimuli were significantly evidenced. RS patients looked at social stimuli very much longer than ASD patients, and among other considerations this could be considered as one more endophenotype that makes RETT so different from ASD.

Eye tracking technologies allowing the quantification of eye gaze have been used more and more since the beginning of this century. The first publication on their use aimed to determine visual fixation patterns during viewing of naturalistic social situations as predictors of social competence in individuals with autism ${ }^{14}$. Since then some aspects of eye tracking have been used as outcome measures in studies on $\mathrm{ASD}^{15,16,17}$, and many centers have been using them clinically for diagnostic assessment or even therapeutic interventions in individuals with ASD.

Few years later, Baptista et al. ${ }^{13}$ confirmed in an objective way the intentionality of RS girls' eye gaze ever declared subjectively by parents, caregivers, therapists and educators, suggesting its use to explore these patients' cognitive abilities, about which we still know so little. In 2009, Velloso et al..$^{18}$ reported that RS girls could not show with eyes the recognition of basic concepts (color, shape, size, and position) when assessed with eye tracking system. These authors discussed some limitations of that pilot study, such as the short time of

Table 1. Means, standard deviations and range of percentage of visual fixation on targets areas for Rett syndrome (RT) and autism spectrum disorders (ASD) patients and typically developing (TD) children.

\begin{tabular}{lcccc}
\hline \multirow{2}{*}{ Groups } & \multirow{2}{*}{ Picture 1 } & Picture 2 & \multicolumn{2}{c}{ Picture 3 } \\
\cline { 3 - 5 } & & & Left side (baby) & Right side (clock) \\
\hline RT & $87.7 \pm 9.3(60.3-96.7)$ & $76.6 \pm 25.6(16.2-96.7)$ & $75.8 \pm 15.7(33.4-90.2)$ & $9.2 \pm 4.1(5.5-20.9)$ \\
ASD & $35.7 \pm 23.3(16.7-91.7)$ & $13.5 \pm 11.7(0-37.4)$ & $17.8 \pm 9.3(6.5-34.9)$ & $69.5 \pm 10.9(52.6-87.5)$ \\
TD & $57.2 \pm 31.0(4.4-88.9)$ & $33.7 \pm 24.5(1.2-68.2)$ & $44.5 \pm 30.0(0.4-89.3)$ & $17.9 \pm 19.9(0-69.0)$ \\
p-value & 0.001 & 0.001 & $<0.001$ & $<0.001$ \\
\hline
\end{tabular}



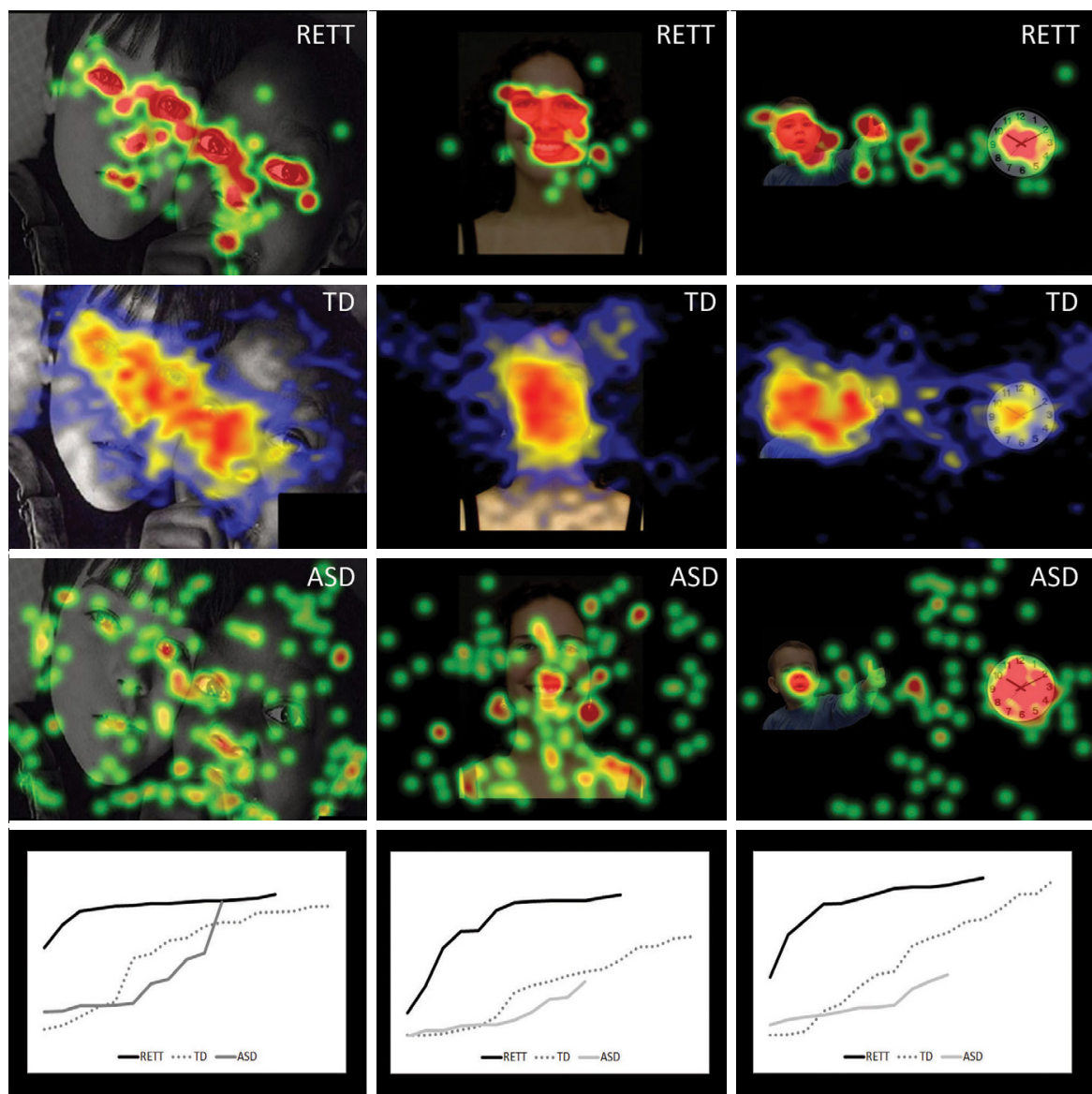

Figure 2. Illustrative example of visual fixation for Rett syndrome patients, TD children and ASD patients. Areas in red are those at which users looked for longer time. In the last line are representative curves of visual fixation percentage of each user for each picture in a crescent scale (considering the baby in the picture 3 ).

exposure to the stimuli ( 4 seconds) and the way the concepts was teach to those children. Recently, the study was replied with longer exposure time ( 8 seconds) and with a more systematic but not yet adequate way to teach these basic concepts to RS girls, and the results were the very same ${ }^{19}$.

A little later, Vignoli et al. ${ }^{20}$ used eye tracking technology in an attempt to establish correlations between neurophysiological and cognitive function in RS, and measured the length of fixation during 5 seconds for recognition, matching of pairs, and semantic categorization. Their preliminary findings indicated that epilepsy characteristics and EEG patterns suggestive of epileptic encephalopathy should be considered prognostic factors in neuropsychological outcome of RS patients, especially concerning the input phase (attention) of information processing. On the other hand, they did not find a close relationship between cognitive impairment and the use of a specific antiepileptic drug.

Recently, researchers of the Montefiori Medical Center ${ }^{21,22,23}$ used eye tracking technology in RS patients to assess their social preferences, to determine their basic features of nonverbal cognitive processes, such as characteristics of their visual fixation pattern (meaningful $\mathrm{x}$ random) and visual attention (in response to novelty), and to examine attention and recognition memory for faces and patterns. In the first study, RS girls demonstrated a tendency towards socially weighted stimuli (social preferences), and looked longer at eyes compared to mouth and nose. The following study reported that RETT girls demonstrated a preference for novel and salient stimuli in a way that normally developing children do. In the last study, the authors combined eye tracking

Table 2. Person's coefficient ( $r$ ) for correlating age and percentage of visual fixation on targets areas for Rett syndrome (RT) and autism spectrum disorders (ASD) patients and typically developing (TD) children.

\begin{tabular}{lcccc} 
Groups & Picture 1 & Picture 2 & Left side (baby) & Picture 3 \\
\cline { 4 - 5 } RT $(n=14)$ & $-0.56^{*}$ & $-0.47^{\star}$ & -0.02 & 0.31 \\
ASD $(n=11)$ & -0.08 & 0.33 & 0.12 & 0.09 \\
TD $(n=17)$ & $0.41^{*}$ & $0.43^{\star}$ & $0.34^{\star}$ & 0.09 \\
\hline
\end{tabular}

*Significant correlations for $p \leq 0.05$. 
technology with a visual paired-comparison (VPC) paradigm and found out that patients with RS could recognize faces and patterns, although their recognition was poorer than that of age-matched participants.

Now we can add to such objective and systematic findings that patients with RS are undoubtedly more socially engaged than those with ASD and even than younger TD children, although such social engagement tends to decrease with age in RS and, as expected, to increase in young TD children.

This negative correlation between age and social engagement in patients with RS is not difficult to understand when we consider all the physiological suffering affecting them along the life since the first manifestations of the disease, especially the breathing irregularities, low $\mathrm{O}_{2}$ saturation, seizures, very frequent gastrointestinal and orthopedic problems. Other point is that their neuromotor condition (apraxia, inability to use hands, manual stereotypies etc.) associated with the consequent non-verbal and very limited communication reduce considerably their opportunities for social life and for social interests. At last, a number of families tend to reduce more consistent interactions with and for their daughters when they get the adulthood, since parents get older, sometimes sick, and sometimes even die. So the maintenance of their social engagement depends on a lot of conditions, differently from patients with ASD who show no social interests independently of their ages.

It was already observed that epileptic characteristics can be associated with poorer attention in patients with $\mathrm{RS}^{20}$. New studies are needed now to understand the physiological and environmental conditions which can interfere both in the social engagement and the cognitive abilities of such population, so that better and more realistic interventional strategies can be developed.
The differences observed in visual fixation at social stimuli of patients with RS and TD children are perhaps superestimated, since they were not age-matched in our study. We sure understand that TD young children are not the more adequate control to understand social preferences in RS; on the other hand, comparisons between RS and TD children are not an easy or even feasible task, since age-matched groups, especially considering older patients, would probably result in huge developmental differences, and to match them by intellectual tests is still impossible. Our clinical experience along 50 years show us that is very difficult to follow rigorous scientific criteria when studying RS, especially regarding the composition of a realistic control group.

Our study has some limitations especially represented by the difficulties in composing age/gender-matched groups. RS patients and TD children were all females, while ASD patients were all males. It is a fact that RS and ASD are significantly more frequent in females and males, respectively, what has reflected in our samples very strongly. In our next steps in this research line we will compare visual fixation in social stimuli of only aged-matched girls with RS and ASD, so that such variables can be controlled.

In spite of these evident fragilities, our results show that RS patients present social domain more preserved than other cognitive aspects, at least regarding what we know up to now, indicating probably more functional areas which may be focused on in the development of new therapeutic and leisure strategies.

It is a fact that eye tracking technologies have made possible to understand ever better not only the cognitive pathways of patients without verbal communication and, in the case of RS, without motor possibilities, but also the different outcomes involving RS and ASD.

\section{References}

1. Marchetto MCN, Carromeu C, Acab A, Yu D, Yeo GW, Mu Y et al. A model for neural development and treatment of Rett syndrome using human induced pluripotent stem cells. Cell. 2010;143(4):527-39. http://dx.doi.org/10.1016/j.cell.2010.10.016

2. Amir RE, Van den Veyver IB, Wan M, Tran CQ, Francke U, Zoghbi HY. Rett syndrome is caused by mutations in X-linked MECP2, encoding methyl-CpG-binding protein 2. Nat Genet. 1999;23(2):185-8. http://dx.doi.org/10.1038/13810

3. Milunsky JM, Lebo RV, Ikuta T, Maher TA, Haverty CE, Milunsky A. Mutation analysis in Rett syndrome. Genet Test. 2001;5(4):321-5 http://dx.doi.org/10.1089/109065701753617462

4. Cuddapah VA, Pillai RB, Shekar KV, Lane JB, Motil Kj, Skinner SA et al. Methyil-CpG-binding protein 2 (MECP2) mutation type is associated with disease severity in Rett syndrome. J Med Genet. 2014;51(3):152-8. http://dx.doi.org/10.1136/ jmedgenet-2013-102113

5. Takahashi S. [Clinical features in Rett syndrome:MECP2-, CDKL5- and FOXG1 related disorders]. No To Hattatsu. 2014;46(2):117-20. Japanese.
6. Zhao Y, Zhang X, Bao X, Zhang Q, Zhang J, Cao G et al. Clinical features and gene mutational spectrum of CDKL5-related diseases in a cohort of Chinese patients. BMC Med Genet. 2014;15(1):24. http://dx.doi.org/10.1186/1471-2350-15-24

7. Schwartzman JS, Bernardino A, Nishimura A, Gomes RR, Zatz M. Rett syndrome in a boy with a 47,XXY karyotype confirmed by a rare mutation in the MECP2 gene. Neuropediatrics. 2001;32(3):162-4. http://dx.doi.org/10.1055/s-2001-16620

8. Fu F, Liu HL, Li R, Han J, Yang X, Min P et al. Prenatal diagnosis of foetuses with congenital abnormalities and duplication of the MECP2 region. Gene. 2014;546(2):222-5. http://dx.doi.org/10.1016/j.gene.2014.06.012

9. Charman T, Pickles A, Simonoff E, Chandler S, Loucas T, Baird G. IQ in children with autism spectrum disorders: data from the Special Needs and Autism Project (SNAP). Psychol Med. 2011;41(3):619-27. http://dx.doi.org/10.1017/S0033291710000991

10. Schwartzman JS. Epilepsia e autismo infantil. Temas Desenvolv. 2000;9(49):5-8. 
11. Kanemura H, Sano F, Tando T, Sugita K, Aihara M. Can EEG characteristics predict development of epilepsy in autistic children? Eur J Paediatr Neurol. 2013;17(3):232-7.http://dx.doi.org/10.1016/j.ejpn.2012.10.002

12. Baio J, editor. Prevalence of autism spectrum disorder among children aged 8 years. MMWR Surveil Summ. 2010;63(2):1-21.

13. Baptista PM, Mercadante MT, Macedo EC, Schwartzman JS. Cognitive performance in Rett syndrome girls: a pilot study using eyetracking technology. J Intellect Disabil Res. 2006;50(9):662-6. http://dx.doi.org/10.1111/j.1365-2788.2006.00818.x

14. Klin A, Jones W, Schultz R, Volkmar F, Cohen D. Visual fixation patterns during viewing of naturalistic social situations as predictors of social competence in individuals with autism. Arch Gen Psychiatry. 2002;59(9):809-16. http://dx.doi.org/10.1001/archpsyc.59.9.809

15. Guastella AJ, Mitchell PB, Dadds MR. Oxytocin increases gaze to the eye region of human faces. Biol Psychiatry. 2008;63(1):3-5. http://dx.doi.org/10.1016/j.biopsych.2007.06.026

16. Andari E, Duhamel JR, Zalla T, Herbrecht E, Leboyer M, Sirigu A. Promoting social behavior with oxytocin in high-functioning autism spectrum disorders. Proc Natl Acad Sci USA. 2010;107(9):4389-94. http://dx.doi.org/10.1073/pnas.0910249107

17. Rice K, Moriuchi JM, Jones W, Klin A. Parsing heterogeneity in autism spectrum disorders: visual scanning of dynamic social scenes in school-aged children. J Am Acad Child Adolesc Psychiatry. 2012;51(3):238-48. http://dx.doi.org/10.1016/j.jaac.2011.12.017
18. Velloso RL, Araújo CA, Schwartzman JS. Concepts of color, shape, size and position in ten children with Rett syndrome. Arq Neuropsiquiatr. 2009;67(1):50-4. http://dx.doi.org/10.1590/S0004-282X2009000100013

19. Schwartzman JS, Velloso RL, Santos S. Concepts of color, shape, size, position, and evidences of social preferences in 14 Rett syndrome patients. In: 3rd European Rett Syndrome Conference "Research Update and Peventive Management"; 2013 Oct 17th-19th; Maastricht, The Netherlands. Leidschendam: European Rett Syndrome Conference Maastricht Foundation; 2013.

20. Vignoli A, Fabio RA, La Briola F, Giannatiempo S, Antonietti A, Maggiolini S et al. Correlations between neurophysiological, behavioral, and cognitive function in Rett syndrome. Epilepsy Behav. 2010;17(4):489-96. http://dx.doi.org/10.1016/j.yebeh.2010.01.024

21. Djukic A, McDermott MV. Social preferences in Rett syndrome. Pediatr Neurol. 2012;46(4):240-2. http://dx.doi.org/10.1016/j.pediatrneurol.2012.01.011

22. Djukic A, McDermott MV, Mavrommatis K, Martins CL. Rett syndrome: basic features of visual processing: a pilot study of eye-tracking. Pediatr Neurol. 2012;47(1):25-9. http://dx.doi.org/10.1016/j.pediatrneurol.2012.04.009

23. Rose SA, Djukic A, Jankowski JJ, Feldman JF, Fishman I, ValicentiMcdermott M. Dev Med Child Neurol. 2013;55(4):364-71. http://dx.doi.org/10.1111/dmcn.12085 